ERRATA

SILVA, C. A. Estudos Fundamentais e Aplicações Envolvendo Hormônios Esteróides por meio de Eletroforese Capilar. USP - SP, 2008.

\begin{tabular}{|c|c|c|c|c|}
\hline Página & Parágrafo & Linha & Onde se lê & Leia-se \\
\hline 51 & Figura 3.1 & 3 & $\mathrm{R}_{2}=\mathrm{H}$ & - \\
\hline 71 & 20 & 3 & dez & oito \\
\hline 90 & - & - & $\begin{array}{l}\text { 3.2.1.2. Extração líquido- } \\
\text { líquido }\end{array}$ & 3.2.1.2. Extração \\
\hline 101 & 20 & 3 & Tabela 3 & Tabela 4.3 \\
\hline 112 & Figura 5.1 & 3 & $\mathrm{R}_{2}=\mathrm{H}$ & - \\
\hline 114 & 20 & 8 & disposição & descarte \\
\hline 122 & - & 9 & [18] & {$[34]$} \\
\hline 125 & - & - & 4.1.2 Tensão analítica & 4.1.2 Tensão aplicada \\
\hline 131 & 20 & 3 & $\begin{array}{l}\text { o método é satisfatório, } \\
\text { uma vez que, a }\end{array}$ & a \\
\hline 156 & 10 & 3 & estradiol & etinilestradiol \\
\hline 164 & 10 & 2 & estradiol variando de 97,8 & etinilestradiol variando de 98,8 \\
\hline 165 & 10 & 1 & $\begin{array}{l}\text { estradiol em adesivos } \\
\text { transdérmicos comerciais } \\
\text { em diferentes lotes }\end{array}$ & $\begin{array}{l}\text { ETE e LEV em comprimidos } \\
\text { comerciais }\end{array}$ \\
\hline 165 & $\begin{array}{l}\text { Título da } \\
\text { tabela } 6.5\end{array}$ & 1 & $\begin{array}{l}\text { Resultados obtidos na } \\
\text { determinação de estradiol } \\
\text { (adesivos transdérmicos) }\end{array}$ & $\begin{array}{l}\text { Resultados obtidos na } \\
\text { determinação de ETE e LEV em } \\
\text { comprimidos comerciais }\end{array}$ \\
\hline
\end{tabular}

\title{
Pagina 131
}

Tabela 5.4. Método de validação relativo à exatidão: teste de recuperação.

\begin{tabular}{cccc}
\hline $\begin{array}{c}\text { AMOSTRA } \\
\text { COMERCIAL }\end{array}$ & $\begin{array}{c}\text { PADRÃO } \\
\text { ADICIONADO } \\
\left(\mu \mathrm{g} \mathrm{mL}^{-1}\right)\end{array}$ & $\begin{array}{c}\text { PADRÃO } \\
\text { ENCONTRADO } \\
\left(\mu \mathrm{gmL}^{-1}\right)\end{array}$ & $\begin{array}{c}\text { RECUPERAÇÃO } \\
(\%)^{*}\end{array}$ \\
\hline 1 & 20,0 & 20,3 & 101,5 \\
1 & 25,0 & 24,9 & 99,60 \\
1 & 30,0 & 30,1 & 100,2 \\
\hline
\end{tabular}


Pagina 156

Tabela 6.4. Método de validação relativo à exatidão: teste de recuperação.

\begin{tabular}{cccc}
\hline $\begin{array}{c}\text { AMOSTRA } \\
\text { COMERCIAL }\end{array}$ & $\begin{array}{c}\text { PADRÃO } \\
\text { ADICIONADO } \\
\left(\mu \mathrm{g} \mathrm{mL}^{-1}\right)\end{array}$ & $\begin{array}{c}\text { PADRÃO } \\
\text { ENCONTRADO } \\
\left(\mu \mathrm{gmL}^{-1}\right)\end{array}$ & $\begin{array}{c}\text { RECUPERAÇÃO } \\
(\%)^{*}\end{array}$ \\
\hline 1 & 24,0 & 23,7 & 98,70 \\
1 & 30,0 & 29,9 & 99,80 \\
1 & 36,0 & 36,0 & 100,1 \\
\hline
\end{tabular}

Pagina 165

Tabela 6.8. Método de validação relativo à exatidão: teste de recuperação.

\begin{tabular}{cccc}
\hline $\begin{array}{c}\text { AMOSTRA } \\
\text { COMERCIAL }\end{array}$ & $\begin{array}{c}\text { PADRÃO } \\
\text { ADICIONADO } \\
\left(\mu \mathrm{g} \mathrm{mL}^{-1}\right)\end{array}$ & $\begin{array}{c}\text { PADRÃO } \\
\text { ENCONTRADO } \\
\left(\mu \mathrm{gmL}^{-1}\right)\end{array}$ & $\begin{array}{c}\text { RECUPERAÇÃO } \\
(\%)^{*}\end{array}$ \\
\hline 1 & 24,0 & 23,8 & 99,1 \\
1 & 30,0 & 29,8 & 99,4 \\
1 & 36,0 & 35,6 & 98,8 \\
\hline
\end{tabular}

